\title{
Redesigning Harvard Library's Website with User Research at Every Step
}

\author{
Amy Deschenes \\ Harvard University, USA
}

\section{Introduction}

In July 2018, Harvard Library launched a re-envisioned and redesigned library.harvard.edu. The site brings together two properties: the former library.harvard.edu, a Drupal-hosted website with information on the Harvard Library organization, and hcl.harvard.edu, a static website with information about libraries related to Harvard College, which is the four-year, undergraduate liberal arts program at Harvard. Our goal for the website was to build something easy to use and "endlessly helpful." The four guiding principles of the website are to:

1. put the user at the center of everything we do,

2. make information accessible, not just available,

3. know that the website will never be done, and

4. use open source solutions and practices.

This paper takes a closer look at the first guiding principle and explores the different ways in which we infused the project with user research in order to keep the project user-focused. We constantly asked for feedback, tested our assumptions, and adjusted our thinking based on what we learned. We kicked off the project with discovery research to determine our focus, conducting interviews with current and potential users. This work resulted in building four personas that we used to help keep our project conversations and decisions user-centered. When the web team had disagreements about the goals for a page or content strategy, we would put ourselves in the shoes of these personas, adopting their perspective to help guide our decision-making.

While using the personas kept our discussions and planning user-focused, they did not substitute for regular user research. We used a variety of UX (user experience) methods in our research, frequently turning to user interviews, brief surveys, and prototype testing. The other major segment of our research during the project centered on the site's navigation structure and content labels. We used card sorting and tree testing to get feedback on how we organized the content on our site. We made sure that each user research study had discrete goals with specific research questions and used whichever UX method was most appropriate for our inquiry.

The research was conducted by the project team with current and future potential users. The studies ranged from informal, on-the-spot research in a cafe or library to formal task-based, think-aloud usability studies in a usability lab. The Harvard project team included one full-time UX researcher, but other members of the team, including our content strategist, designer, and product owner, facilitated testing sessions. The UX researcher was responsible for defining the research questions based on what the team wanted to learn, creating the protocol, and organizing the test sessions. Members of the team that participated in data collection were provided with training or briefings before working with users. Results and recommendations were summarized and presented to the team by the UX researcher.

During our project, we used an agile software development process with a scrum framework. An agile development process uses an iterative development process and scrum organizes the work into timeboxes, also called sprints. In our team, each sprint lasted two weeks. In order to fit effective user research into this process, we conducted research before the coding to build a new page, whenever possible. In addition to this regular testing of designs, we added a recurring UX check-in meeting to each sprint. At this meeting, the 
entire team would plan for upcoming research needs, review recent findings, and make decisions on what actions to take based on insights. These meetings proved to be extremely useful and kept the entire team apprised of the research and findings on a regular basis.

The website redesign took place from September 2017 to July 2018, although the discovery research was conducted before the official project kick-off, from February to April 2017. The research we conducted is defined by Erika Hall as applied design research, rather than pure research, so we only collected enough data that would help us make a decision about our designs and provide us with useful insights. ${ }^{1}$ Over the course of the project, we had input from over 200 of our users in the research studies that we conducted. What follows is some of the methods we used and lessons we learned from the research.

\section{Discovery Research and Personas}

In January 2017, Harvard Library began a discovery research phase of our website redesign project. The website was hosted on aging servers, was running on an old version of Drupal, and had outdated front-end design that was not mobile-friendly. We also needed to rethink our content strategy and how we served users, especially those who might not know what resources the library can provide for them. In order to better understand our users, we partnered with a UX consulting agency to conduct preliminary research on ideas for new features and content through user interviews.

The discovery phase of our project happened well before we even wrote the request for proposal (RFP) to hire a vendor for the site's design and development. We wanted to conduct research with users to understand where the gaps were in our current website, what we needed to build, and how users expected the library website to work for them. We collaborated with an outside UX consulting firm to conduct interviews with students, researchers, faculty, and staff during this phase of the research. The interview guide (see Appendix A) contained questions related to how members of the community currently used our library website, along with their pain points and mental models related to the site and libraries. We also asked about what was missing from the library's website experience.

The most important finding of the research was that most users were completely unfamiliar with the website. The main Harvard Library website (not the catalog) provides information on library spaces, services, tools, and staff. Most users were unfamiliar with these resources unless someone, usually a helpful librarian, had specifically pointed them out. Users thought of the library catalog, HOLLIS, as the "main library website." Additionally, most users interviewed said that they typically start at Google or Google Scholar when they begin their research because of its familiarity and ease of use.

Interview participants also said that they were unaware of the availability of library resources outside of the library catalog. Resources like online research guides, workshops, citation tools, and in-person research support were unknown to most participants. Users expressed a need for an easy way to learn about these kinds of resources to avoid the common feeling of "I wish I had known about this sooner" that many participants expressed about certain tools and services.

Finally, the interviews spurred new ideas for features that the library website could provide. The most significant of these was an idea for a way to find library study spaces, cafes, and meeting rooms. We had heard in other user studies that there was a need for this kind of tool, but the discovery research provided the greatest evidence that building some kind of study spot finder would fulfill a need expressed by a wide variety of students.

After reviewing the outcomes of the interviews and aligning them into themes, we created four personas to represent the user goals and motivation of different user types. Personas are an artifact from user research that can be used as a tool to keep a web project user-focused. Personas are specific, detailed, and in-depth profiles of potential users. They are not based in demographics, but rather, represent research themes that serve multiple demographics. Each persona is based in real user research-in the case of 
the library.harvard.edu redesign project, the results of the user interviews conducted in the discovery research phase of the project.

Based on the interviews, we created four personas: Overstretched Owen, Rigorous Richard, Engaged Ella, and Curious Carlotta. Each persona has several elements: a photo, a representative quote, biographical information, UX goals, a brief profile, and a summary of habits and pain points. During our project, the web team relied on these personas to create user stories and keep our decision-making user-focused. We found ourselves asking questions like, "What would Richard want on a page like this?" and "How's Owen going to arrive at this page?" By giving the personas tangible identities, they became a useful tool for the web team when having complicated conversations and making difficult decisions. (See Appendix B.)

\section{Prototype Testing and 5-Second Tests on the Library Detail Pages and Find a Space App}

The team frequently used prototype testing to get user feedback on design mockups during the website redesign project. Rather than wait until a new page was built for the site, we tested high-fidelity design mock-ups with users to get their input and make adjustments to the design before it was built. By using this method, we were able to get potential users' first impressions and understand how they would expect the functionality to work, with minimal demand on our team's resources.

One of the first pages that we designed for the new website was the library detail page. On the library detail page, users can find information about each library in the Harvard Library system. These pages needed to support a variety of libraries, archives, and collections, so they had to be flexible, allowing for a large amount of detail or a small amount of basic information. We tested the design of this page using content related to the Cabot Library, our main library for science and engineering students. The testing took place in this library, and 35 undergraduate students participated.

For the library detail page prototype test, our goals were to learn what types of content students would prioritize, to get their initial impressions of the design, and to understand the language they would use to describe certain sections of content. We set up the test using a Qualtrics survey. Before showing participants the design, we asked what the most important information related to Cabot Library was and what features they wish they had known sooner. To collect impressions of the design (Figure 1), we showed them the design for five seconds, a technique known as the " 5 -second test" 2

(https://articles.uie.com/five_second_test/), and then asked them if they agreed with the following statements using a 5-point Likert scale from "strongly agree" to "strongly disagree":

- The site looks easy to use.

- The layout of the site is clear and simple.

- The site is visually interesting.

- The site is friendly and warm.

- The site provides information that is useful to me. 
Figure 1, Library Detail V1

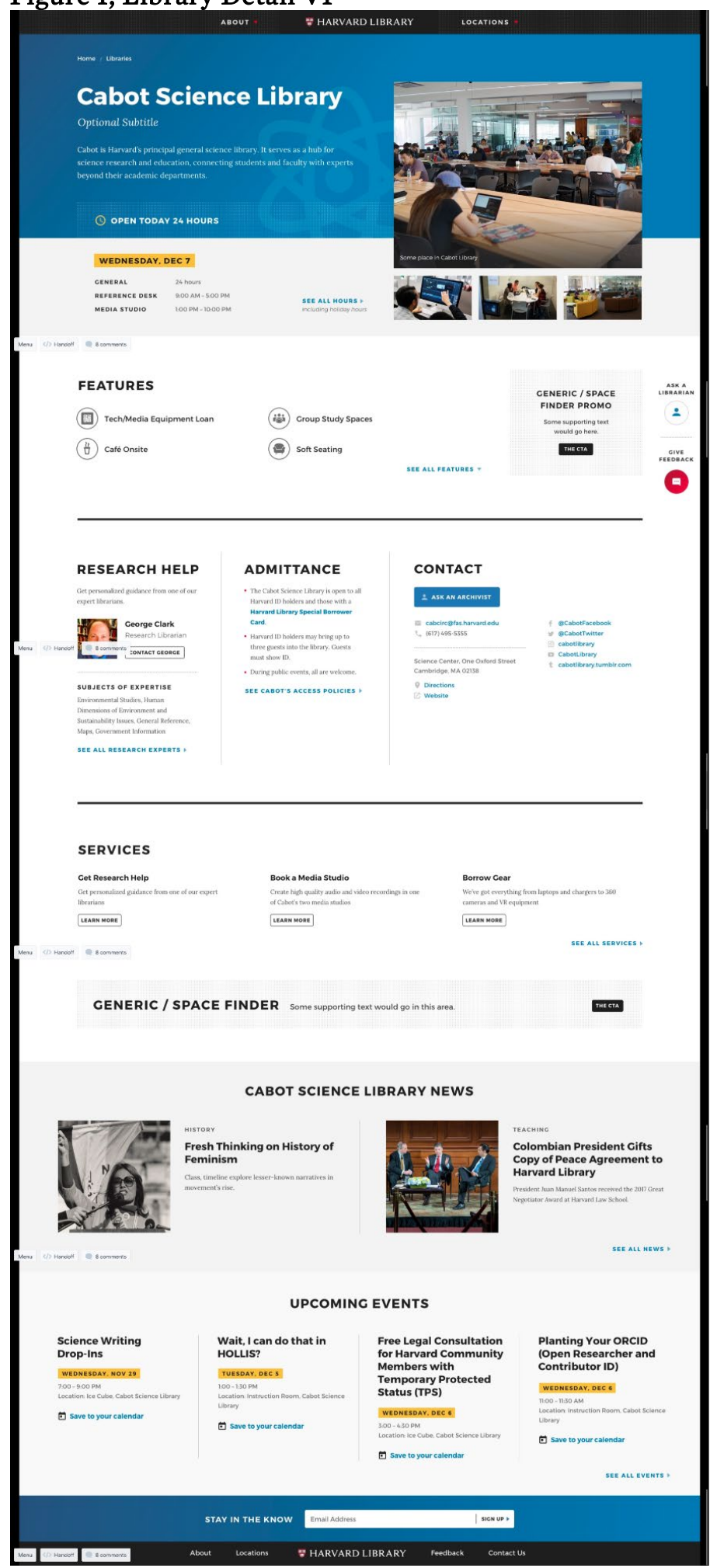

We then asked how they would label certain sections of content so we could better understand what words users would choose to describe information about amenities, technology, and access policies. 
What we learned from 35 student participants from the prototype test influenced the second iteration of the library detail design. Students wanted to see a photo that was more representative of the library space itself, rather than the exterior of the science building, and found the first impression of the page to be too cluttered with information. Students gave feedback including, "Reduce the amount of text" and "The design needs more contrast." The team used this feedback and reviewed the content needs of the various libraries; the second version of the library detail page design simplified the first impression of the page, while still providing the key information at the top. We also created a template that could be easily customized depending on if the library was more study-space-focused or collection-focused, or a blend (Figures 2 and 3).

Figure 2, Library Detail V2, Cabot

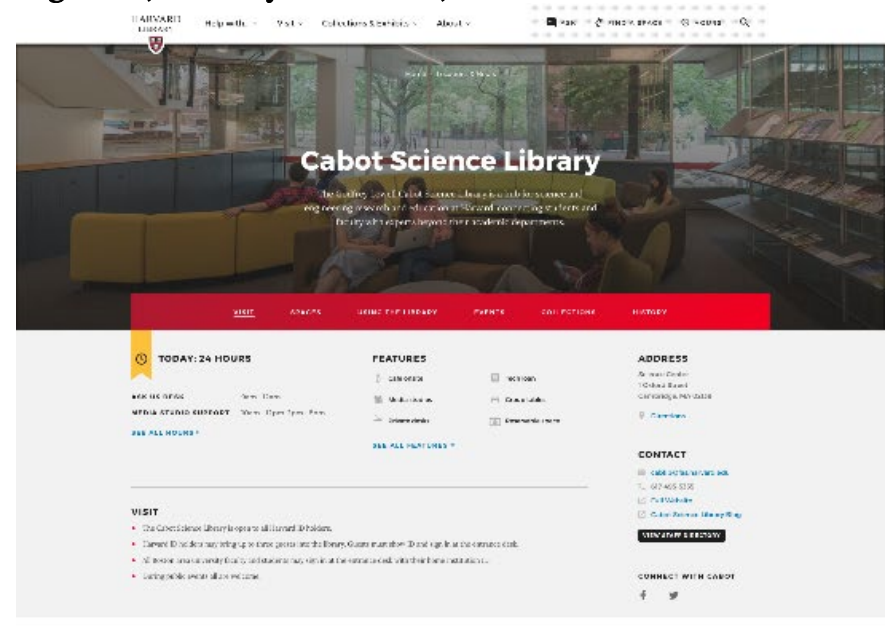

SPACES

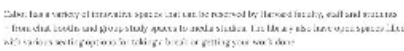
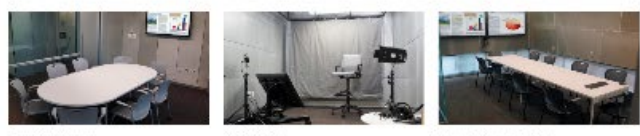

cosupstout hoom

Netio 8 tuxios

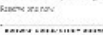

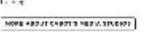

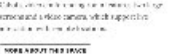

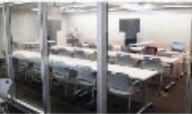

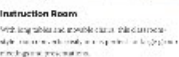

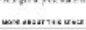

BROWSE ALL CABOT SPACES

maxiona

BOOKING SPACE FOR AN EVENT

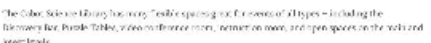
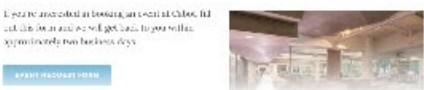

USINC THE LIBRARY

now To.
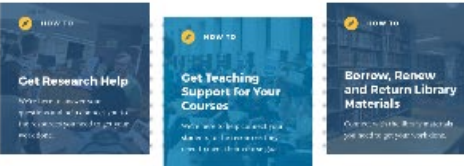


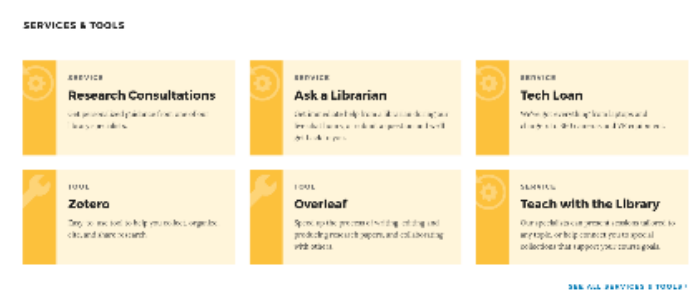

EVENTS

UPCOMINC EVENTS

Halloween Nation: A Scason

Talk by Lestey Bannatym

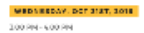

Media Copyrioht. Fair Use,
Protecting Your Work

Protecting Your Work
cises, watemso

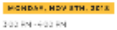

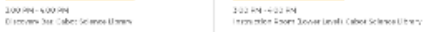

COLLECTIONS
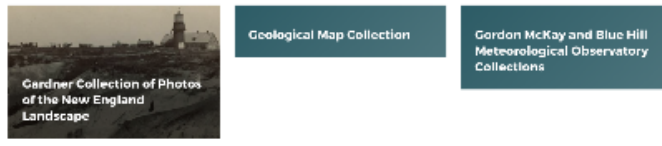

HISTORY

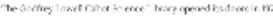

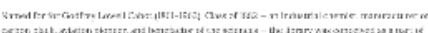

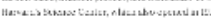

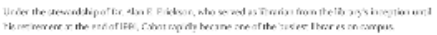

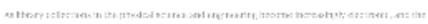

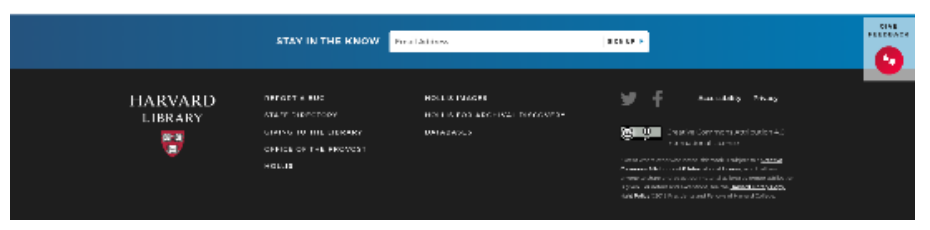


Figure 3, Library Detail V3, Houghton

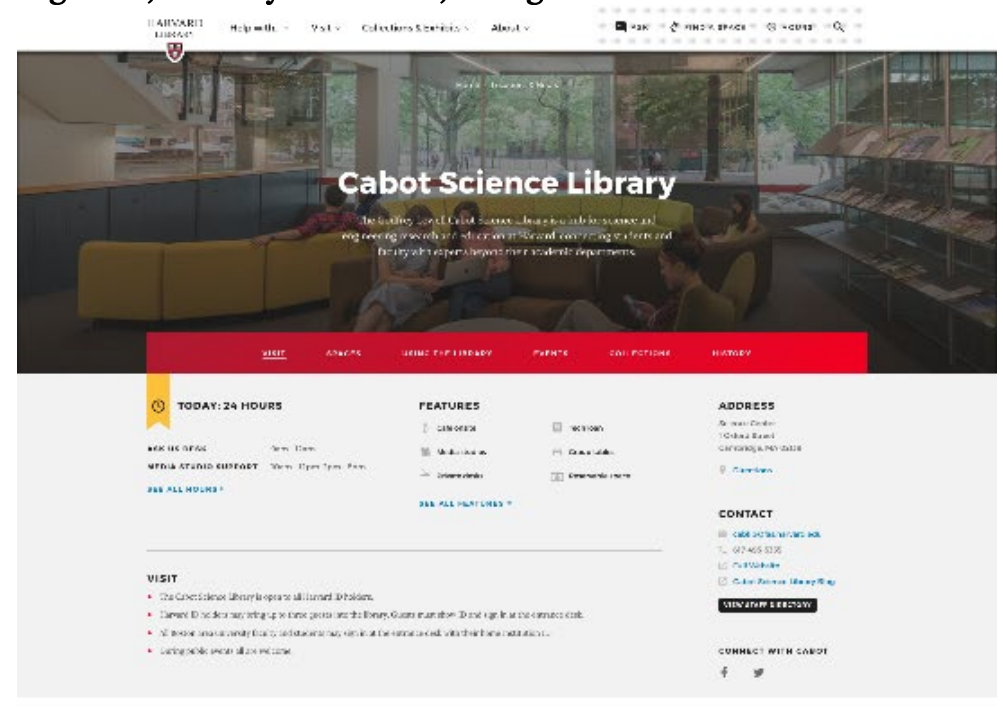

SPACES

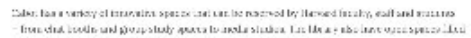

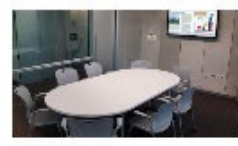

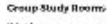

(w)

Kanex

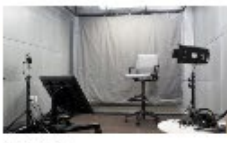

Nestia stunios

(2)

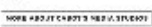

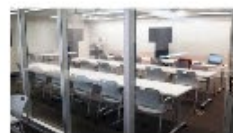

Inetrustisn Roam

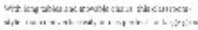

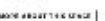

BROWSE ALL CABOT SPACES

masase

BOOKING SPACE FOR AN EVENT

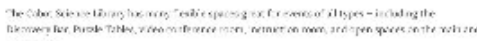

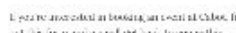

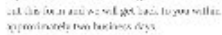

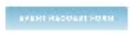

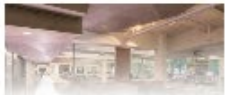

USINC THE LIBRARY

How To...
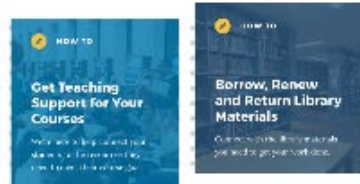

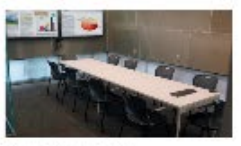

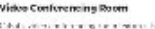

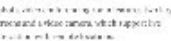

sermoneriesa

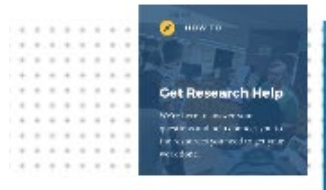




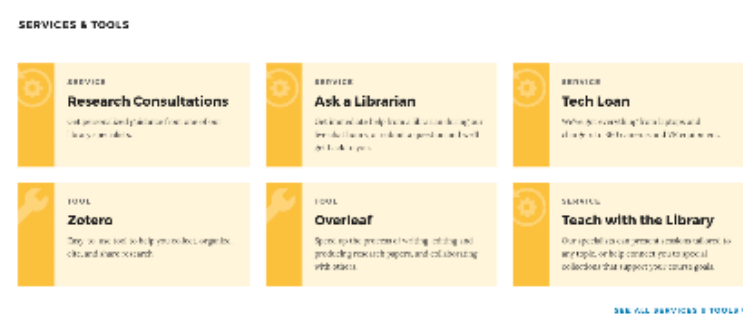

EVENTS

UPCOMINC EVENTS

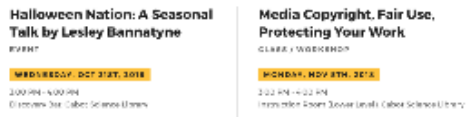

COLLECTIONS

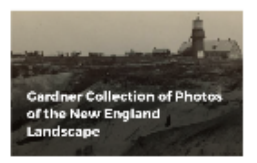

Geological Map Collection

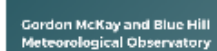

Metworological Observatory
Collectlons

HISTORY

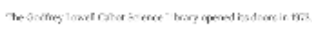

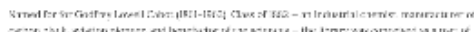

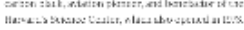

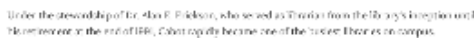

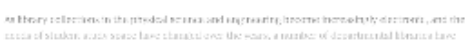

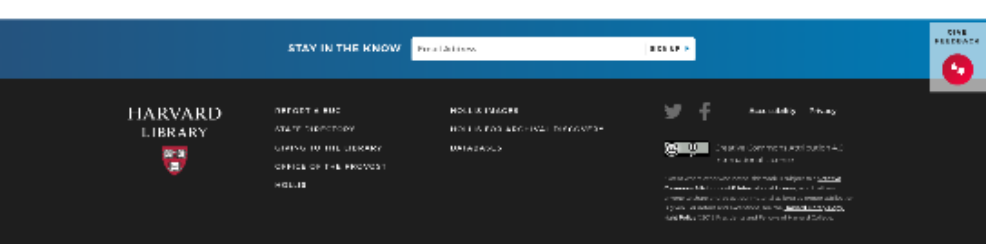

We also conducted prototype testing on our Find a Space app. We built this app because we learned from our initial discovery research that students had trouble finding study spaces in the libraries and understanding the variety of spaces that exist. The layout and design are inspired by other study space finders like those from Cambridge University's Space Finder ${ }^{3}$ and University of Washington's Scout. ${ }^{4}$ The design has three distinct columns with which users can interact independently, but affect the adjacent panels. The first column lists space filters, the second column provides details, including photos, of each room, and the third contains a map with the space locations plotted (Figure 4). 
Figure 4, Harvard Library Find a Space

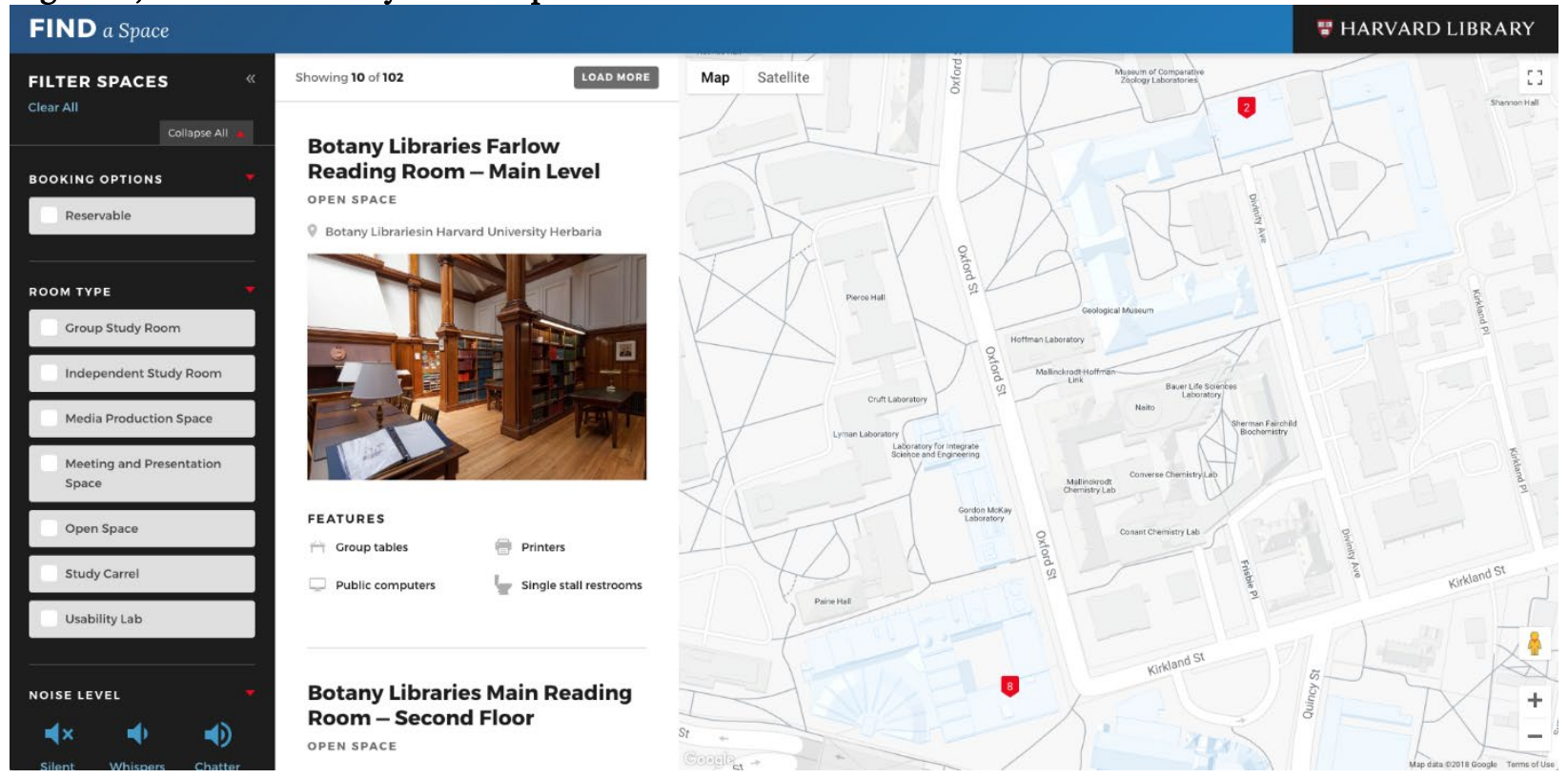

Since the design was based on existing, successful study space finder apps, the focus of our research was on the content organization and labels used within the app, rather than collecting feedback on the design. We did want to know if it was useful for students to have the map taking up a large portion of the screen, but that was the only specific design question we wanted to investigate in this prototype test. In this test, we showed participants a physical paper prototype, and then had a staff member ask questions about the labels, order of the filters, and the map. The staff member recorded participant answers in a Qualtrics survey to keep the data organized and easy to analyze.

A total of 32 students participated in this testing, which took place on the spot in a library entry space. We were particularly interested in better understanding the labels related to furniture. We asked a "this or that" style question to better understand what terminology would be more intuitive for students. The results are summarized in Table 1.

Table 1, Language Preferences for Furniture Labels

\begin{tabular}{|l|l|}
\hline Private tables/desks (72\%) & Study carrels (28\%) \\
\hline Shared tables/desks (13\%) & Group tables (87\%) \\
\hline Standing desks (80\%) & Standing workstations (20\%) \\
\hline Soft seating (16\%) & Couches/upholstered furniture (84\%) \\
\hline Movable furniture (87\%) & Configurable furniture (13\%) \\
\hline
\end{tabular}

We also asked about which features were most important when choosing a space. The results for preferred order of space features by importance is summarized in Table 2. 
Table 2, Preferred Order of Space Features

\begin{tabular}{|l|l|}
\hline 1 & Seating choices \\
\hline 2 & Outlets \\
\hline 3 & Work surface choices \\
\hline 4 & Food \& drink allowed \\
\hline 5 & Food \& drink available to buy \\
\hline 6 & Charging stations \\
\hline 7 & Whiteboards \\
\hline 8 & Printers/copiers/scanners \\
\hline 9 & Lockers \\
\hline
\end{tabular}

Finally, regarding the map question, 23 out of 32 participants found the map to be useful. They described it as "really convenient" and "important," especially for meeting up with a group. The one thing they said that they would change is to add an option to make the map collapsible so that it could be hidden if the user chose to do so. This is a feature we may add in to the app in the future. We used the feedback on the labels and word choices to make the app more usable from the first version, since the testing was conducted before any coding was done.

\section{Card Sorting and Tree Testing, Site Navigation}

One of the most complex issues with any website redesign is how the site's main navigation menu is structured. We launched our beta site with a small amount of content and a placeholder navigation system to give us time to formulate the site's content strategy and work with users to define a usable information architecture. We used two UX methods to create and evaluate our navigation structure: card sorting and tree testing. Card sorting helped us define how users would group and label the content, while tree testing allowed us to test two different navigation structures against each other, and create a final version that was most usable. We used the online tree testing and card sorting tools from Optimal Workshop to carry out this research.

In a card sort, users are given a list of "cards." Each card represents an area of content on the website. Cards can represent a large area of content, such as "Hours." Or cards could represent a single page, like a specific tool, such as "Zotero." We then ask users to group cards they view as similar and give each group a label.

A specific question the web team had was around a brand-new content type we are calling "How Tos." How Tos will answer the question "How can Harvard Library help me with..." For example, a page titled "How to Get Teaching Support" would pull together all the tools and services related to teaching that we offer. We wanted to know whether users would group all of the How To pages together or whether they would group them with similar content. The results of our card sorting test showed the How To pages are more helpful if they are grouped with similar content, rather than having the navigation menu present them as a long list of How Tos.

One of the other major findings from our card sort testing is that almost every participant used the word "Visit" as a top-level grouping label. Other popular sub-group labels included "Borrowing," "Research," "Media \& Technology," and "Teaching." Armed with this research, the staff from the web team participated in a sketching activity to define the navigation. Eight staff members from the web team each wrote down their own navigation menu. Then we worked in pairs to combine the best parts of each person's navigation 
menu, and then in teams of four. Finally we had two navigation schemes. The group then worked together through the two navigation schemes to come up with the final list of top-level navigation items. The final navigation structure we agreed upon was: Help with..., Visit, Collections \& Exhibits, and About.

We had decided on the top-level navigation headings, but still needed to organize all of the pages on content pieces underneath. This is where tree testing came in. In a tree test, participants are given several tasks and presented with a clickable navigation tree which they use to complete each task as best they can. We used the Harvard Library User Research Center's email list of graduate and undergraduate students to complete the tree test. Half of the 400-person list received Tree Test A, which contained one navigation setup, and the other half received Tree Test B, which contained the other navigation setup. Users were then asked to complete a set of tasks, such as:

You used HOLLIS (the library's catalog) to ask for a book chapter to be scanned and emailed to you. Where can you go to find out how long it will take to be sent to you?

Using the tree testing tool, Treejack, we could easily see which navigation scheme worked best for each task. The tool tracks the click path that the participant used when attempting to complete the task. We reviewed the results of the tree test and took the best aspects of our two navigation setups to create our final navigation menu. The team was particularly confounded by a How To on special collections and archives. Would users expect to find that under "Help with..." or "Collections \& Exhibits"? After testing, we learned that most users looked for that content under "Help with..." so that is where the link to the page now lives.

\section{Conclusion}

Within one week of the website launch in July 2018, we conducted task-based, think-aloud usability testing to understand how undergraduates navigate the site and if there were any obvious pain points. Some of the insights from the usability testing mirrored some of the feedback that we received via our online feedback form. For example, users have trouble locating the option to view library hours by week on the Hours page. This ongoing feedback loop allows us to make informed choices about what enhancements we choose to prioritize. Although the site has already launched, we continue to seek out user feedback to test new features and review any assumptions that we are making.

The discovery research and user testing conducted during the 2018 redesign of library.harvard.edu made a significant, positive impact on our first release. Rather than making choices about the site's design, information architecture, and content based on our preferences, assumptions, or anecdotal feedback, we worked directly with our site's users to make informed decisions. By working with a variety of research methods, depending on our research questions and study goals, we were able to gather the best information to help us move forward in the project. Making user research part of the project process, rather than an afterthought, helped make the site's initial release well-received and usable by our core audience.

-Copyright 2019 Amy Deschenes

\section{Endnotes}

1. Erika Hall, Just Enough Research (New York: A Book Apart, 2013), 5-9.

2. Christine Perfetti, "5-Second Tests: Measuring Your Site's Content Pages," UX Articles by UIE (blog), September 11, 2007, https://articles.uie.com/five_second_test/.

3. "Scout," Accessed October 29, 2018, https://scout.uw.edu/seattle/.

4. "Spacefinder," Accessed October 29, 2018, https://spacefinder.lib.cam.ac.uk/. 


\section{Appendix A}

Discovery Research, Interview Guide Example (Undergraduate Student Interview)

Background

- Please give us a bit of background about yourself. What program are you attending at Harvard?

When do you expect to graduate?

\section{Experiences}

During your time at Harvard, have you used the Harvard Library system at all? For what purpose? Have you used library.harvard.edu?

Talk me through the last time you can remember that you:

- ... used Harvard Library resources [books, data, etc]

- ... For yourself or on behalf of someone else?

- [If interviewee doesn't mention Archives, prompt]

- .... attended an event hosted by the library

- ... interacted with library staff

- ... How did you do it? Phone? Email? In person?

- $\quad$... used the Harvard Library website?

- ... Why? What were you trying to do?

When you were doing or assisting research, how did Harvard Library fit into your overall research process?

- Did you start your search for resources at the library, or did you start elsewhere?

- Were you always been able to find the resources that you were looking for?

- What kinds of resources did you depend on the Library for?

- What kinds of resources did you not expect the Library to have available?

Pain Points

- Considering Harvard Library and associated websites, do you see any major shortcomings that jump out to you?

- What about things that seem to work particularly well?

- Do you feel well-equipped to use the resources that the library provides? Do you feel like you understand how to conduct research as effectively as possible using library collections?

Mental Models

- What does "Library" mean to you?

- What tasks do you expect Harvard librarians to be able to help with? If there were a button for "Ask a Librarian" on the website, what kind of questions might you ask?

- In your mind, what should Harvard Library be responsible for? How well is it achieving these goals today?

- How unified vs. separate do you feel like the various libraries at Harvard are? Do you ever feel like you don't know which library to use for certain resources?

Project

- Is there anything you'd like us to keep in mind as we approach this problem?

- Are you willing to participate in further testing sessions to help us as we refine the vision for the Library site? 


\section{Appendix B}

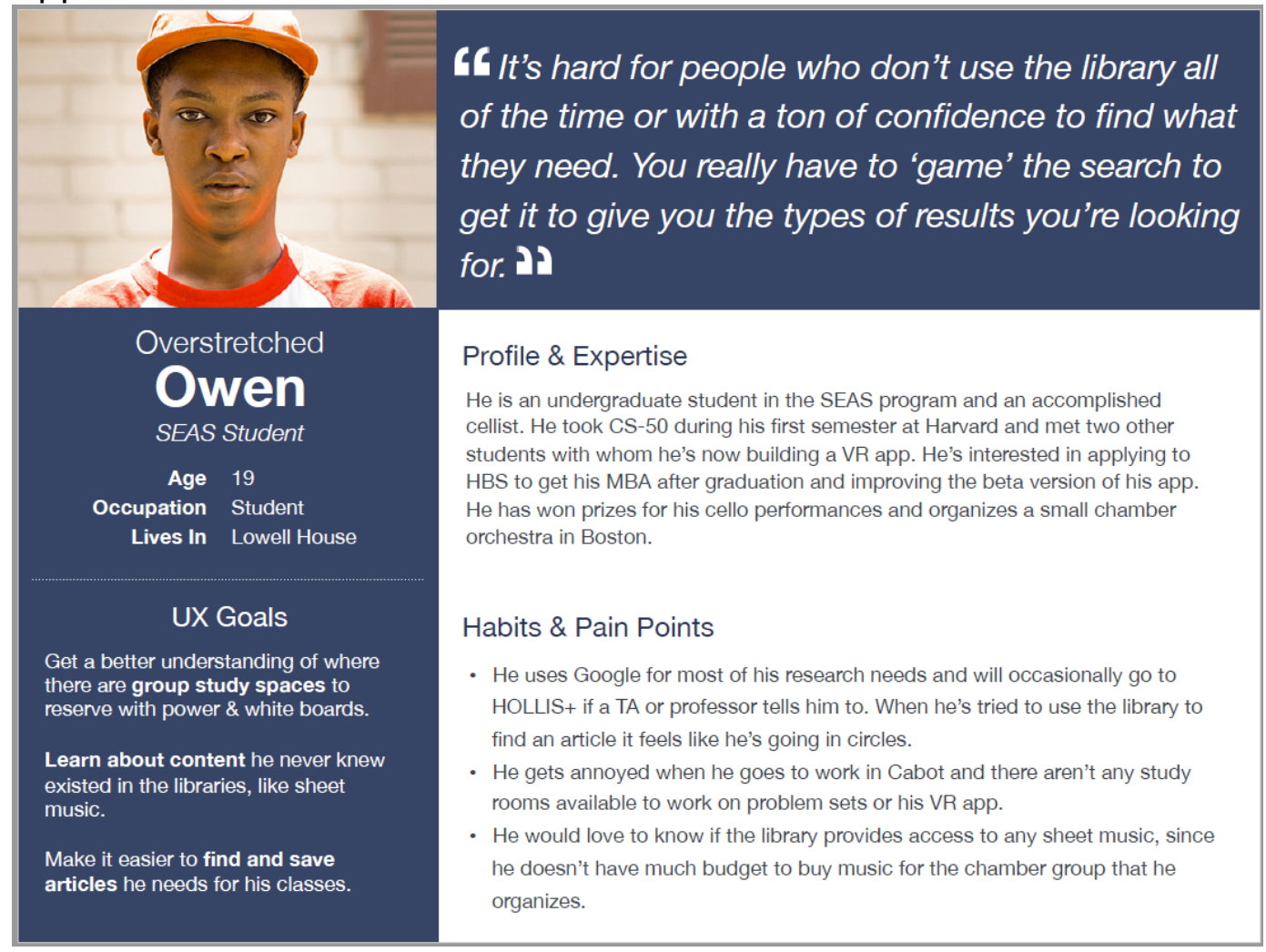

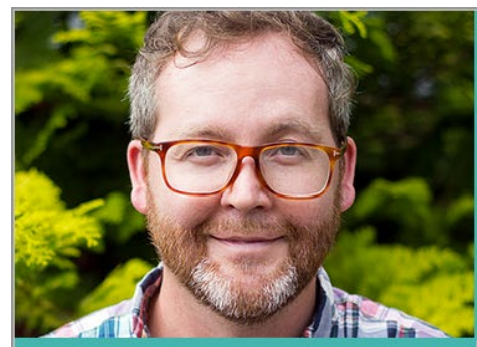

Richard

Visiting Researcher

Age Late 40s

Occupation Research Fellow

Lives In Brooklyn, NY

\section{UX Goals}

Get location details for Harvard libraries $\&$ archives that have the items that he's interested in.

Prepare for his visit and get as much information as possible in advance before arriving at Harvard.

Search all Harvard libraries and archives for digitized resources related to his topic.

\section{$\mathbf{6}$ The thing with archival research is that there is} always more information than what's available online. You can only get so far with the website and then you need to switch to a human. '?

\section{Profile \& Expertise}

$\mathrm{He}$ is a research fellow at Columbia University, studying 18th century religious history of New England. During the day he takes care of his twin boys and does most of his research and writing in the late evening hours. He only uses a keyboard for all of his computing after injuring both of his wrists rock-climbing made it painful to use a mouse.

He has worked with archivists from Harvard via email, but is planning to visit inperson this semester. He wants to access materials from mulitple locations and meet with staff who are subject matter experts. He only has six days to spend in Cambridge and wants to make the most of his trip.

\section{Habits \& Pain Points}

- Starts his research at Google to get to systems like HOLLIS+ \& OASIS.

- Wants to request all of the materials he needs online, in advance of his visit.

- Isn't sure what his onsite access allows him to do; how late can he stay in the library, can he access printers, how does he access articles behind HUID, etc.

- Would like to schedule appointments with staff prior to arrival.

- Unclear to him where he is allowed to work while visiting Harvard. 


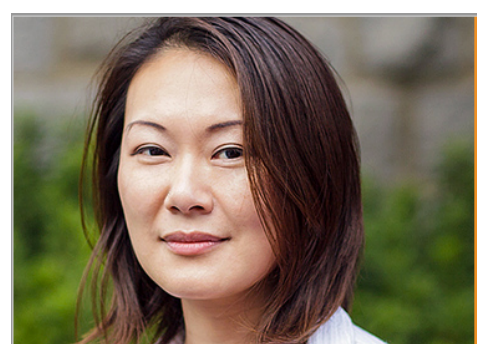

Engaged

Ella

Faculty Member

Age Mid 40s

Occupation Professor

Lives In Belmont, MA

UX Goals

Easily connect with librarians to provide in-class instruction.

Expose students to the vast richness of Harvard's library resources, specifically through library training.

Make searching less overwhelming, especially for students \& connect graduate student advisees to appropriate subject databases.
\& 4 Students are more successful when they take a library training session. It's mind-blowing because they realize how much is available at Harvard and how to do things more efficiently. 2 ?

Profile \& Expertise

She is a faculty member in the Anthropology department and has taught at Harvard for over twenty years. She is an avid hiker and takes weekend trips to western MA with her Australian shepherd, Maisie. She is an advocate for the libraries and serves on the Faculty Advisory Board. She is invested into exposing more students to special collections and advocates that students 'get their hands' on the materials. She prefers to go straight to the anthopology subject databases that she uses all of the time, rather than using HOLLIS+. She advises a number of $\mathrm{PhD}$ students and employs several graduate research assistants.

Habits \& Pain Points

- Keeps her frequently used anthropology databases bookmarked in her browser.

- Recommends students starts with subject databases, rather than HOLLIS+ which returns too many results.

- Wants an easier way to access what Harvard has from ancient Greece \& Egypt.

- Would use HOLLIS+ more if it were easier to save searches and organize favorite articles.

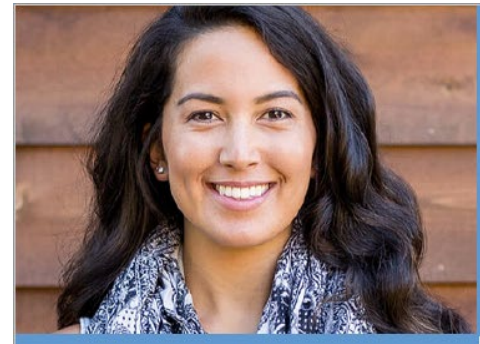

Curious

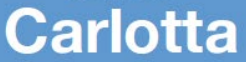

GSE Alum \& DCE Student

Age Early 30 s

Occupation ESL Teacher

Lives In Medford, MA

UX Goals

Get a clear understanding of the privilege rules around borrowing materials and using library spaces.

Access online images owned by Harvard.

Stay abreast of current events at the libraries, esepcially new exhibits.

\section{GC There are striking differences between each} library. When you search in Google it's not always clear whether a library is open or not. You're never sure with all of the different schedules.

\section{Profile \& Expertise}

She is a GSE alum, now taking museum studies courses through DCE. She lives with and takes care of her grandmother and nine-year-old sister. She hasn't been able to find a job as an art teacher, so is taking the museum studies courses to move her career in that direction. She is interested in finding out if she has any special access to resources or library locations because she's an alum. She'd also like to understand if students in her ESL class can visit Harvard exhibits and if there's anything that's free for them to use online.

\section{Habits \& Pain Points}

- She has a busy personal life, but likes to get work done at the library for a quiet 'break' from real life.

- Always feels like the libraries have lots of cool stuff, but it's hard to know how to access it.

- She always hears about exhibits after they close and wants to know how to stay better informed.

- It's challenging for her to find out what libraries she has access to and for how long she can check out books for. 